\title{
Treatment of Iron Tailings at the Forecariah Guinea Mine - Guinea Conakry*
}

\author{
A. Kali and W. K. Buah
}

Kali, A. and Buah, W. K. (2016), "Treatment of Iron Tailings at the Forecariah Guinea Mine - Guinea Conakry”, Ghana Mining Journal, Vol. 16, No. 1, pp. 83 - 88.

\begin{abstract}
Forecariah Guinea Mine SA (FGMSA) in Guinea - Conakry mines and processes Iron ore. About 0.5 Mt of tailings material has already been generated with additional 4000 tons generated daily. This paper presents a re-treatment technology for the Iron tailings obtained from the processing plant of FGMSA. Metallurgical tests were carried out on the tailings to determine which process route gives the most satisfactory result in terms of recovery and cost. Two representative samples (FCOPD-01 and FCDOP-02), taking from the tailings, were investigated. Particle Size Distribution (PSD) and chemical composition of various size fractions of representative samples of the tailings were performed. Dense Medium Separation (DMS) and Magnetic Separation (WHIMS) were also performed on a number of size fractions. The initial chemical composition of the various size fractions shows that the highest Fe grades were present in the $+1 \mathrm{~mm}$ fractions at $58.8 \%$ and $58.6 \%$ for FCOPD01 and FCOPD-02 respectively. The PSD of the tailings also indicated a mass yield of $77.9 \%$ for the $+1 \mathrm{~mm}$ fraction and $22.1 \%$ for the $-1 \mathrm{~mm}$ fraction. Contaminant Oxides, such as $\mathrm{Al}_{2} \mathrm{O}_{3}$ and $\mathrm{SiO}_{2}$ tend to be higher in the finer size fractions $(-1$ $\mathrm{mm})$ of both samples. Result from the DMS analysis performed on the $(-4+0.5) \mathrm{mm}$ fraction shows an underflow mass yields of $45.98 \%$ with $\mathrm{Fe}$ grade of $65.55 \%$ and overflow mass yield of $53.08 \%$ with $\mathrm{Fe}$ grade of just $13.5 \%$. Magnetic separation (WHIMS) results on the $(-4+0.5) \mathrm{mm}$ samples also gave varied mass yield and Fe grade at different magnetic intensities (3000 Gauss, 6000 Gauss and 10,000 Gauss). However, the highest Fe mass yield and grade produced from the magnetic separation were $18.10 \%$ and $50.8 \%$ respectively. The results show that DMS technique has the potential to re-treat the tailings at FGMSA.
\end{abstract}

Keywords: Treatment, Iron ore, Tailings, Magnetic separation, Dense Medium Separation

\section{Introduction}

The Forecariah Guinea Mine Societe Anonyme, a subsidiary of Bellzone Australia, mines and export iron ore. The company uses the open pit system of mining. The mined ore which averages about $54 \%$ $\mathrm{Fe}$ (mostly hematite) is marginally below what could be considered a direct shipping ore (DSO). The focus of the processing plant is therefore to upgrade the mined ore to achieve an export quality product ready to be sold into the commercial market.

The processing technology involves crushing the run of mine (ROM) to $-70 \mathrm{~mm}$ through a jaw crusher followed by screening at a screen aperture size of $30 \mathrm{~mm}$, which is in closed circuit with a secondary crusher to generate a $-30 \mathrm{~mm}$ product. The crushed product is then screened at $8 \mathrm{~mm}$ to generate two products; the lumps and the fines. The lumps $(-32+8) \mathrm{mm}$ averaging $62 \% \mathrm{Fe}$ is ready for the market as a DSO, whiles the fines $(-8 \mathrm{~mm})$ fraction with $53 \% \mathrm{Fe}$ is considered as tailings and currently stock-piled at the tailings dam.

About 0.5 Mt of these fines (tailings) has already been generated and stockpiled, with additional 4,000 tons added daily after the commissioning of the new crushing plant.
With this huge amount of tailings already generated, the mine is currently running out of space to store the additional tailings been generated daily.

Besides the spacing challenge being faced by the mine, the tailings also poses an enormous environmental and ecological challenge for the mine as slimes are being washed into the surrounding vegetation anytime there is a huge down pour around the mine area.

An initial investigation into the tailings properties has shown that with the right processing route, it is possible to upgrade the tailings to a commercial value, at recovery rate of at least $70 \%$.

This $70 \%$ recovery translates to $0.35 \mathrm{Mt}$ of saleable product that could be generated from the existing tailings aside creating more space for continuous operation at the plant.

Presently the main challenge with tailings is that, it contains higher amount of contaminants such as Silica $\left(\mathrm{SiO}_{2}\right)$ and Alumina $\left(\mathrm{Al}_{2} \mathrm{O}_{3}\right)$ which are mostly in the finer fraction $(-1 \mathrm{~mm})$ making it unsuitable for the Iron industry. The challenge is therefore to remove these contaminants and raise the iron grade in the tailings to a saleable grade $(>55 \%)$. This would not only create additional 
space for the storage of tailings but also generate additional income for the mine. Efforts have been made to recover iron value from fine tailings material (Hu and Sun, 2016; Ajaka, 2009). Sahoo et al. (1980) and Krishna et al. (2013), also discussed mineralogical characteristics of some off grade Iron ore in India and the use of Heavy Medium Separation in the processing of Iron Ore was also discussed by Voges (1975).

This research aims at providing a technology for retreatment of the tailings. To achieve this, Particle size distribution (PSD) of the tailings and chemical composition of the various size fractions were performed on samples from the tailings, Dense Medium Separation (DMS) and Wet High Intensity Magnetic Separation (WHIMS) were also performed on a number of size fractions. Consequently, a flowsheet for retreatment of the tailings has been proposed.

\section{Resources and Methods Used}

Two samples were collected from the tailings storage facility (fines dump). These tailings (Fines), as already mentioned were generated from the crushing and screening of the ore mined at the Forecariah Guinea mines site, Yemboyelli. The final screen undersize ( $-8 \mathrm{~mm}$ fraction), considered as the fines (Tailings), were used for this project. Consequently, two samples FCOPD 1 and FCOPD 2 were taken for the project. Each of the samples weighed approximately $100 \mathrm{~kg}$.

A sub-sample was also taken and screened at various sizes, from $25 \mathrm{~mm}$ down to $45 \mu \mathrm{m}$ to examine the particle size distribution and also the chemical composition of the various size fractions using XRF. Dense Media Separation (DMS), was performed on two size fractions, $(-8+4) \mathrm{mm}$ and ($4+1) \mathrm{mm}$ fractions. This was followed by wet high intensity magnetic separation (WHIMS) on the (-1 $+0.3) \mathrm{mm}$ fraction. The primary forces that significantly affect magnetic separation are magnetic force, gravity and hydrodynamic forces.

The magnetic force Fm is given below:

$\mathrm{Fm}=\mathrm{K} \times \mathrm{Xm} \times \mathrm{H} \times[\mathrm{dH} / \mathrm{dx}] \times \mathrm{V}$

Where,

$\mathrm{Fm}=$ Magnetic force,

$\mathrm{K}=$ Constant,

$\mathrm{Xm}=$ Intensity of Magnetisation related to magnetic susceptibility,

$\mathrm{H}=$ Magnetic intensity

$\mathrm{dH} / \mathrm{dx}=$ Magnetic gradient

$\mathrm{V}=$ Volume of particle.

The magnetic separation test work was conducted on the $(-1+0.3) \mathrm{mm}$ fraction, using a Davis Tube Wash (DTW). The Davis tube magnetic separator comprises a $25 \mathrm{~mm}$ glass tube that is gyrated at an angle between the poles of a high-intensity electromagnet. The magnetic intensity between the poles is controlled by means of an adjustable autotransformer.

The tube is gyrated between the poles in a reciprocating motion at a frequency controlled by an adjustable driving motor. The tube is filled with water, and water at a fixed flow rate is added to the top of the tube and gravitates through the tube to the discharge. These particles mix with the water and gravitate to the magnetic field. The magnetic particles are caught between the poles of the electromagnet while the nonmagnetic particles are carried to the discharge end of the tube by the flow of water. Chemical analysis of the feed, magnetics and non-magnetics samples generated from the test work was performed using XRF.

A number of scouting tests were conducted to determine the impact of magnetic field strength. Tests at 3000, 6000, and 10,000 Gauss were conducted.

\section{Results and Discussion}

\subsection{Samples Characteristics}

Both samples consist of reddish brown powder with specific gravity of 2.2. The average assayed head for both samples were $54.5 \%$ for $\mathrm{Fe}, 6.8 \%$ for $\mathrm{SiO}_{2}, 6.1 \%$ for $\mathrm{Al}_{2} \mathrm{O}_{3}$ and $8.4 \%$ LOI. The samples contain mostly hematite and with some subordinates amount of clay and quartz. The as received samples were subjected to wet sieve analysis and the chemical composition of various size fractions were determine. The results are given in Table 1.

From the sieve analysis and the chemical analysis of the various size in Table 1, it could be seen that as the particle size reduces the amount of $\mathrm{SiO}_{2}$ increases with $\mathrm{Al}_{2} \mathrm{O}_{3}$ also marginally increases above the head grade. This could be the results of the way the ore body was formed. Most deposits of iron ore in the world are found in rocks known as banded iron formations (BIFs). These are sedimentary rocks that have alternating layers of iron-rich minerals and a fine-grained silica rock called chert, as seen in Fig. 1. As comminution increases, the degree of liberation of these minerals increases, hence the reason why we have so much silica in the very fine fractions.

However, it is possible to recover the $+1.18 \mathrm{~mm}$ size fractions by just screening it off. This could give a mass yield of above $77 \%$ and average Iron grade of $58.6 \%$. The average grade for Silica $\left(\mathrm{SiO}_{2}\right)$ and Alumina $\left(\mathrm{Al}_{2} \mathrm{O}_{3}\right)$ for the $+1.18 \mathrm{~mm}$ fraction, marginally failed to meet the grade stipulated for a DSO, which is $<3.5$ for Silica and $<5$ for Alumina. The impurities could however be minimised by blending it with high grade ore to reduce the overall impurities. 
Table 1: Wet Sieve Analysis of the Tailings and Chemical Composition of Various Size Fractions

\begin{tabular}{|c|c|c|c|c|c|c|c|c|c|}
\hline & Distribution & $\begin{array}{l}\mathrm{Fe} \\
\%\end{array}$ & $\begin{array}{c}\mathrm{SiO}_{2} \\
\%\end{array}$ & $\begin{array}{l}\mathrm{Al}_{2} \mathrm{O}_{3} \\
\%\end{array}$ & $\begin{array}{l}\mathrm{MnO} \\
\%\end{array}$ & $\begin{array}{l}\mathrm{CaO} \\
\%\end{array}$ & $\begin{array}{l}\text { MgO } \\
\%\end{array}$ & $\begin{array}{l}\mathbf{P} \\
\%\end{array}$ & $\begin{array}{l}S \\
\%\end{array}$ \\
\hline Calc Head & & 55.2 & 6.9 & 6.1 & 0.1 & $\mathbf{0}$ & $\mathbf{0}$ & 0.1 & $\mathbf{0}$ \\
\hline Sizing (mm) & $\%$ & & & & & & & & \\
\hline+25.000 & 6.6 & 59.2 & 4 & 5.8 & 0.1 & 0 & $<0.001$ & 0.1 & 0.1 \\
\hline$-25.00+16.00$ & 5.3 & 59.1 & 4.7 & 5.8 & 0.1 & 0 & 0 & 0.1 & 0 \\
\hline$-16.00+12.50$ & 7.5 & 60 & 3.8 & 5.6 & 0.1 & 0 & $<0.001$ & 0.1 & 0 \\
\hline$-12.50+8.000$ & 5.8 & 58.9 & 4.3 & 5.6 & 0.1 & 0 & $<0.001$ & 0.1 & 0 \\
\hline$-8.000+6.300$ & 17 & 58.7 & 4.8 & 5.5 & 0.1 & 0 & 0 & 0.1 & 0 \\
\hline$-6.300+4.000$ & 14.5 & 60.4 & 3.6 & 5.3 & 0.1 & 0 & $<0.001$ & 0.2 & 0 \\
\hline$-4.000+2.000$ & 10.5 & 58 & 4.8 & 5.9 & 0.1 & 0 & $<0.001$ & 0.2 & 0 \\
\hline$-2.000+1.180$ & 10.6 & 55.9 & 4.8 & 6.1 & 0.1 & 0 & $<0.001$ & 0.2 & 0.1 \\
\hline$-1.180+0.500$ & 5.4 & 52.8 & 8 & 6.4 & 0.1 & 0 & 0 & 0.2 & 0.1 \\
\hline$-0.500+0.250$ & 3.3 & 47.1 & 13.1 & 6.3 & 0.2 & 0 & 0 & 0.2 & 0.1 \\
\hline$-0.250+0.125$ & 2.9 & 38.3 & 21.6 & 6 & 0.2 & 0 & 0 & 0.1 & 0 \\
\hline$-0.125+0.075$ & 2.1 & 35.2 & 24.4 & 5.9 & 0.1 & 0.1 & 0.1 & 0.1 & 0 \\
\hline$-0.075+0.045$ & 1.7 & 37.6 & 21.1 & 6.5 & 0.1 & 0.1 & 0.1 & 0.1 & 0 \\
\hline-0.045 & 7.0 & 35.7 & 16.5 & 9.7 & 0.1 & 0.1 & 0.2 & 0.1 & 0 \\
\hline
\end{tabular}

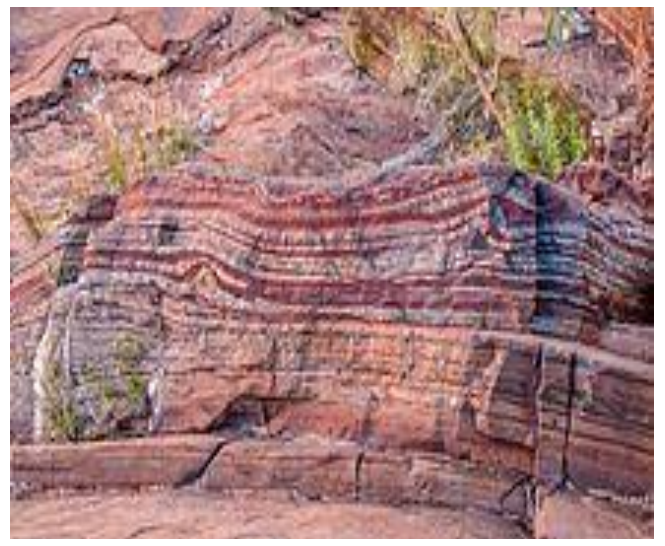

Fig 1. Band Iron Formation

\subsection{Dense Medium Separation}

The $(-8+1.18) \mathrm{mm}$ which was considered to be below what is considered a DSO due to its low iron value and also high impurities levels, was subjected to a DMS process. This was also confirmed by analyzing the various size fractions from the PSD performed on the fines. It also shows that, below $+1.18 \mathrm{~mm}$, iron grades in the individual size fractions decreased, presenting a simple upgrade option of screening the finer material from the coarser. A sub fraction $(-4+1.18) \mathrm{mm}$ was also subjected to the same DMS process and the two results were compared.

Two distinct size fractions $(-8+4) \mathrm{mm}$ and $(-4$ $+1.18) \mathrm{mm}$ were subjected to the same dense medium with specific gravity of 3.4. Table 2 shows the results of how the various size fractions responded to the DMS process.

The result shows that the $(-4+1.18) \mathrm{mm}$ fraction responds well to DMS than the $(-8+4) \mathrm{mm}$ fraction in terms of yield, $\mathrm{Fe}$ and $\mathrm{SiO}_{2}$ grade. From Table 2 the underflow yield for the $(-8+4) \mathrm{mm}$ fraction is $27 \%$ comparing to a yield of $46 \%$ for the $(-4+$ 1.18) mm. Other impurities such as $\mathrm{Al}_{2} \mathrm{O}_{3}$ and $\mathrm{Mn} 0$ were also low in the $(-4+1.18) \mathrm{mm}$ fraction. And this could be attributed to the degree of liberation of the two products.

Fig. 2 shows the concentrate and tails samples from a dense media test work trial. The darker coloured product is clearly the concentrate separated from the tailings product.

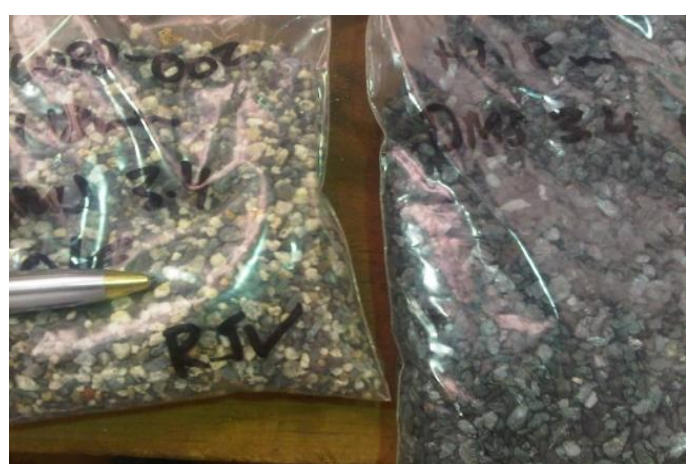

Fig. 2 Dense Medium Separation Products 
Table 2: DMS Result on $(-8+4) \mathrm{mm} \&(-4+1.18) \mathrm{mm}$ Fine Fractions

\begin{tabular}{|c|c|c|c|c|c|c|c|c|c|c|}
\hline SAMPLE & Weight & $\mathbf{F e}$ & $\mathrm{SiO}_{2}$ & $\mathrm{Al}_{2} \mathbf{O}_{3}$ & MnO & $\mathrm{CaO}$ & MgO & $\mathbf{P}$ & $\mathbf{S}$ & LOI (1000) \\
\hline & $\mathrm{g}$ & $\%$ & $\%$ & $\%$ & $\%$ & $\%$ & $\%$ & $\%$ & $\%$ & $\%$ \\
\hline \multicolumn{11}{|l|}{$\begin{array}{l}\text { FCOPD-001 } \\
(-8+4 \mathrm{~mm})\end{array}$} \\
\hline \multicolumn{11}{|l|}{ DMS SG 3.4} \\
\hline Calc. Head & 820.0 & 48.60 & 23.40 & 1.12 & 0.08 & 0.02 & 0.06 & 0.021 & 0.002 & 0.48 \\
\hline Underflow & 221.4 & 64.82 & 3.79 & 1.41 & 0.04 & 0.02 & 0.04 & 0.025 & $<0.001$ & 0.71 \\
\hline Overflow & 598.6 & 7.81 & 53.10 & 0.91 & 0.09 & 0.02 & 0.07 & 0.019 & 0.003 & 0.40 \\
\hline \multicolumn{11}{|l|}{$\begin{array}{l}\text { FCOPD-001 } \\
(-4+1.18 \mathrm{~mm})\end{array}$} \\
\hline DMS SG 3.4 & & & & & & & & & & \\
\hline Calc. Head & 887.4 & 37.43 & 37.20 & 1.34 & 0.13 & 0.01 & 0.05 & 0.029 & 0.001 & 0.71 \\
\hline Underflow & 408.0 & 65.55 & 4.59 & 1.70 & 0.04 & 0.00 & 0.01 & 0.023 & $<0.001$ & 0.65 \\
\hline Overflow & 479.4 & 13.50 & 77.59 & 1.27 & 0.20 & 0.02 & 0.08 & 0.034 & 0.001 & 0.76 \\
\hline
\end{tabular}

\subsection{Magnetic Separation: Wet High Intensity Magnetic Separation (WHIMS)}

The results of the magnetic separation tests are presented in Table 3, from which it could be seen that, 10,000 Gauss recorded the highest mass yield of $19.5 \%$, followed by 6000 Gauss at a yield of $10.4 \%$ and at 3000 Gauss the yield was $7.2 \%$.
However, the Fe grades at 10,000 Gauss and 6000 Gauss were $48.93 \%$ and $54.78 \%$ respectively, which is below the target grade for the export market. At 3000 Gauss the Iron grade was $57.87 \%$, which is within the acceptable grade for a DSO but the level of impurities is way beyond the acceptable grade.

Table 3 WHIMS Result on $(-4+0.5)$ mm Size Fraction

\begin{tabular}{|c|c|c|c|c|c|c|c|c|c|c|}
\hline SAMPLE & Weight & $\mathbf{F e}$ & $\mathrm{SiO}_{2}$ & $\mathrm{Al}_{2} \mathrm{O}_{3}$ & MnO & $\mathrm{CaO}$ & MgO & $\mathbf{P}$ & $\mathbf{S}$ & LOI (1000) \\
\hline & $\mathrm{g}$ & $\%$ & $\%$ & $\%$ & $\%$ & $\%$ & $\%$ & $\%$ & $\%$ & $\%$ \\
\hline \multicolumn{11}{|c|}{ FCOPD-WHIMS $(-4+0.5) \mathrm{mm}$} \\
\hline Calc. Head & 4100.0 & 46.80 & 13.93 & 8.49 & 0.14 & 0.03 & 0.02 & 0.161 & 0.057 & 9.32 \\
\hline 3000 Gauss & 296.6 & 57.87 & 12.34 & 6.97 & 0.14 & 0.05 & 0.03 & 0.155 & 0.039 & 6.61 \\
\hline 6000 Gauss & 429.2 & 54.78 & 14.41 & 7.85 & 0.16 & 0.03 & 0.02 & 0.144 & 0.051 & 8.09 \\
\hline 10,000 Gauss & 801.3 & 48.93 & 11.58 & 8.25 & 0.14 & 0.03 & 0.01 & 0.156 & 0.055 & 8.84 \\
\hline MIDS & 768.0 & 47.97 & 11.67 & 8.68 & 0.14 & 0.03 & 0.01 & 0.165 & 0.060 & 9.53 \\
\hline $\begin{array}{l}\text { Non- } \\
\text { Magnetics }\end{array}$ & 2332.6 & 44.08 & 17.33 & 8.79 & 0.14 & 0.03 & 0.02 & 0.161 & 0.058 & 9.36 \\
\hline
\end{tabular}




\subsection{Conceptual Flow Sheet}

From the test work, the following conceptual flow sheet (Fig. 3) can be proposed:

(i) Installation of a wet screening plant that will cut the tailings (fines from the crushing plant) at $+4 \mathrm{~mm}$. This will produce an Iron concentrate of 58.6\% Iron and $77 \%$ mass yield.

(ii) Installation of another screening plant to cut the undersize of the first screen at 1 $\mathrm{mm}$. The oversize $(+1 \mathrm{~mm})$ would be subjected to a dense media separation. This could yield an Iron grade of $65.5 \%$ and $46 \%$ mass yield.

(iii) The undersize $(-1 \mathrm{~mm})$ fraction could be sent to a dewatering cyclone and cut at $0.25 \mathrm{~mm}$ to produce a middling concentrate. The cyclone overflow $(-0.25$ $\mathrm{mm}$ ) could be sent to a thickener for water recovery and subsequent discharge into a slime dam.

\section{Conclusions}

From the PSD analysis of the sample and the chemical analysis of the various size fractions, we could potentially have a mass yield of $77 \%$ and Iron grade of $58.6 \%$ at a cut size of $1.18 \mathrm{~mm}$. This is marginally above the grade considered for DSO and therefore could be sold into the commercial market. It is also possible just by screening at $1 \mathrm{~mm}$ to generate a marketable product. However, a DMS analysis on the $(-4+1.18) \mathrm{mm}$ size fraction provided a better mass yield and Iron grade than what was achieved on the same size fraction by just screening. Therefore, it would be advantageous to cut at a screen size of $4 \mathrm{~mm}$ and subject the $(-4+1)$ $\mathrm{mm}$ fraction to a DMS. This will produce a better screened product and increase the screening efficiency as well. Subjecting the $(-4+1) \mathrm{mm}$ size fraction to DMS also gave a yield of $46 \%$ and Iron grade of $65.5 \%$ and it also has a lower $\mathrm{SiO}_{2}$ grade. Subjecting the $(-1+0.3) \mathrm{mm}$ to a magnetic separation at a magnetic force of 10,000 Gauss through to 3,000 Gauss yielded a product of $57.87 \%$ Iron and $6.40 \%$ mass yield. However, looking at the mass yield and Iron grade results from the magnetic separation, it will be a waste of resources to subject the $(-1+0.3) \mathrm{mm}$ fraction to a magnetic separation at this stage without further

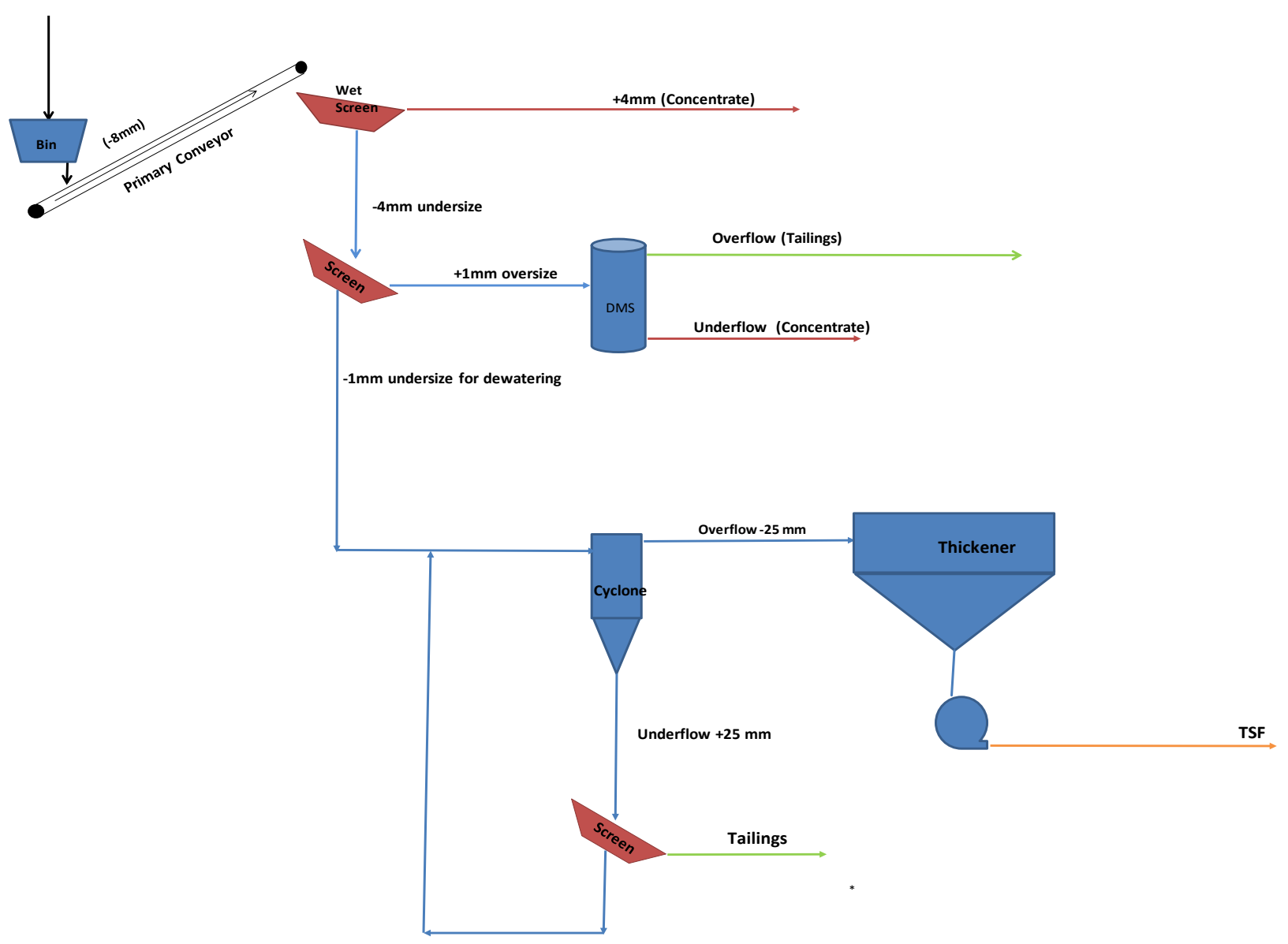

Fig. 3 Conceptual Flow Diagrams for the Fines Upgrade 
investigation, due the level of impurities. Therefore, the magnetic separation aspect could be ignored for now to reduce the initial capital cost for such a project.

By installing the proposed plant to treat the tailings products from the crushing and screening plant, over $70 \%$ of the tailings product could be upgraded to a commercial value for re-sale. This will not only generate additional money for the project but also reduce the amount of space required to store waste from the plant and also mitigate any environmental impact of such huge volume of material. Detailed investigation for the selection of process equipment in terms of its capacity, operation and maintenance cost in handling voluminous amount of tailings at the plants needs to be conducted.

\section{References}

Ajaka E. O. (2009), "Recovering Fine Iron Minerals from Itakpe Iron Ore Process Tailing", ARPN Journal of Engineering and Applied Sciences, Vol. 4, No. 9, 12 pp.

$\mathrm{Hu}, \mathrm{Z}$. and Sun, C. (2016), "A Study on Preparation and Utilization of Tourmaline from Tailings of an Iron-ore Processing Plant", Procedia Environmental Sciences, Vol. 31, pp. 153-161.

Krishna, S. J. G., Patil, M. R., Rudrappa, C., and Kumar, S. P. (2013), "Characterisation and processing of some Iron ore of India", pp 113 120.

Sahoo, R. K., Acharya, B. C., Naik, B. C., Misra, S. K. (1980), "Mineralogical characteristic of some off grade Iron ore in India", International symposium of beneficiation and agglomeration.

Voges, H. C. (1975), "The Use of Heavy Medium Separation in The Processing of Iron Ore", Journal of The south Africa Institute of Mining and Metallurgy, pp $303-306$.

\section{Authors}

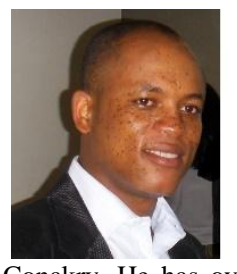

Alexander Kali holds a Diploma in Minerals Engineering from the University of Mines and Technology, UMaT, Tarkwa. He is currently a postgraduate student in Minerals Engineering at the same university. He was the processing manager at FGMSA, an Iron mining company in GuineaConakry. He has over 12 years of experience in the minerals processing industry, having previously worked with companies such as AngloGold Ashanti (Obuasi \& Iduapriem), Newmont Mining Corporation (Ahafo - Ghana) and Golden Star Resources (Bogoso - Ghana). His research interests include processing plants design, control and plant optimisation.

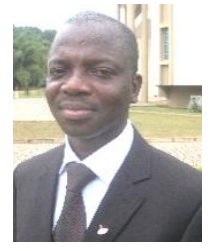

W. K. Buah holds a $\mathrm{PhD}$ in Waste Processing Engineering from the University of Leeds, Leeds, UK and a Master of Science Degree in Minerals Processing Engineering from the Mining Institute of Krivoy Rog, Krivoy Rog, Ukraine. He is currently an Associate Professor at the University of Mines and Technology, Tarkwa, Ghana. His current research interests include minerals processing and extractive metallurgy, waste management, pyrolysis-gasification of wastes and biomass to produce valuable products, including activated carbon for gold adsorption. He is a member of the Society for Mining, Metallurgical and Exploration Engineers (SME) and the Chattered Institute of Waste Management, UK. 